\title{
The Variables of Computer Simulation within Flexible E-Training Environments and their Effects on the Development of 3D Animation Skills for Computer Teachers
}

\author{
Elsaeed E. AbdElrazek \\ Department of Computer Preparing Teacher \\ Dumyat University-Faculty of specific Education \\ Dumyat, Egypt
}

\begin{abstract}
Computer simulation programs are the most modern trend in electronic training systems, which aim at putting the trainee in flexible situations, imitating the actual training situations in terms of interacting with the content. It is also concerned with the proper representation of performances and with procedures that are characterized by simplicity and ease in light of specific rules and consistent with the trainee's own abilities which help to acquire the skills. Therefore, the current research aims at preparing a flexible e-training simulation model in the field of animation based on the interaction between the variable of the display speed pattern (slow-medium-fast) and the information view pattern (previous - next) and measuring the impact of interaction between them on the development of 3D animation skills for computer teachers.
\end{abstract}

The research depended on The Experimental Approach and a sample of (30) computer teachers who were distributed randomly to (6) experimental groups according to the experimental design of the research and its independent variables. The findings are that there are statistically significant differences between the means of the total scores of the Experimental Group in the skill performance which is associated with animation design skills. These differences are due to the interaction between the display speed (slowmedium-fast) and the view pattern within the flexible etraining simulation model for the group which has dealt with the fast-speed simulation model and the previous training situation. This has made the group achieve the highest grades in terms of performance skill compared to other groups.

\section{General Terms}

Computer Simulation- Flexible E-training

\section{Keywords}

Computer Simulation- Flexible electronic traininginformation view pattern (Previous / Next)- 3D animation designing skills -display speed in the simulation model (slowmedium-fast)- Computer Preparing Teacher.

\section{INTRODUCTION}

After the tremendous progress in computer-based training (CBT), the development of e-training environments has become more important to help explain complex information and acquire skills that are difficult to train on in actual situations due to the financial cost or human experience through designing virtual training 3D situations simulating the real-world , providing them with synchronous and asynchronous communication tools , training activities that rely on the trainee to acquire information, developing the skills and supporting his/her motivation towards training.

Simulation Programs are a modern technology used within etraining environments as one of the training with experience model to address one of the weaknesses in traditional training environments: lack of direct experience through designing multiple virtual training situations based on representing the concept of skill performance on two- and three-dimensional animation in a way which achieves the synchronization between time and speed. This approach makes the trainee reaches the maximum mental activity during his/her training and also works on developing his/her ability of self-evaluation [1].

The findings of the study of both Zacharia and Amy [2], [3], indicate the effectiveness of the $3 \mathrm{D}$ simulation programs in the development of skills and using them as treatment programs to raise the efficiency of trainees and highlighting their use in the fields that rely on visualization and creativity, compared to the traditional methods which are based on the role of the trainer. Simulations programs are characterized by their high level of abstraction and their ability to display the skill performance with a high degree of clarity as it reduces the processing requirements in the short-term memory.

PapaStergiou[4], has defined a set of rules and foundations necessary for writing modern training programs for teachers' training as: transforming to e-training environments and using simulation techniques, supporting trainee-centered training strategies, depending on applied simulation models to adjust training activities towards the proper practices, adopting multimedia training curriculum, satisfying the professional needs of the trainees, the flexibility in terms of the variety of options available to the trainees in terms of training requirements and choosing the type of activity, accessing training according to the specific abilities of each trainee in light of his/her own speed, affording the opportunity for trainees to interact with training situations and finally using technical advances in supporting the training such as simulations, E-training, Mobile and SMS

The researcher believes that training programs for computer teachers should develop the aspects related to e-learning, education design, virtual learning environments design and the production of e-courses because design is one of the main basis of computer teacher specialization . 
Moreover, the research of Moreno, R. \& Mayer R.[5], has confirmed that 3D animation skills are difficult to perform for most e-training developers. These skills require the use of visual stimuli to explore the relationships between visual and motion communication. The findings of this research have confirmed the effectiveness of using simulation as an advanced technique for training on animation skills. The group that used simulated training was better than the group that trained with the traditional fixed screen method and the voice explanation for the trainer.

These difficulties in the design of animation may be due to some of the problems that are still ongoing and related to the reality of the work in the training institutions, which are the following: the focusing on the training content on the cognitive aspects at the expense of the technical aspects, the lack of full knowledge of the characteristics of trainees at that stage , training methods and appropriate training activities, inadequate training time, which affects training activities and not repeating their practices, increasing the number of trainees in one group during practical exercises and using the group training method which is not suitable for dealing with animation design skills .

Therefore, it may be useful to design a simulation program that supports individual training or training in small groups to develop the design skills of 3D animation .

\section{RESEARCH PROBLEM}

The development of virtual environments is closely relevant to the tremendous advances in the field of computer simulation. In developing these environments, it is necessary to study simulation variables that may affect trainees' reception of information and their acquisition of the skills .

The researcher has noted that most of the researches on the design of virtual environments have focused on studying only the effect of one variable of the simulation variables within virtual environments such as the research of eka [6], which focused on the variable of viewing visual and motion stimuli within the simulation programs rather than the processes of education and training. This research has concluded that there is an effect of this variable and it varies depending on the nature of the training content and training environments. Whereas the research of Mayer, et al. [7], has dealt with the speed variable in displaying visual stimuli and its effect on the perception of information and performing the skills provided through simulation programs within e-training environments. This research has concluded that the slow or fast speed affects the ability of the trainee in information processing in the short-term memory which affects the processes of analyzing the information and comprehending it.

The researcher also noted the paucity of research which dealt with the effect of the display speed variable pattern and the view variable pattern within $3 \mathrm{D}$ animation flexible e-training environments based on the cognitive and skill aspects of the trainees .

Therefore, the current research attempts to address other variables of the computer simulation variables, namely the display speed pattern ( slow-medium- fast) and the information view pattern (previous-next) within the flexible etraining simulation model and measuring the effect of interaction between them on developing the skills of 3D animation design for computer teachers.

\section{RESEARCH HYPOTHESES}

The research seeks to validate the following hypotheses:

(1) There are no statistically significant differences at the level of (0.05) between the mean scores of the experimental groups in the skill performance associated with animation design skills because the display speed pattern variable (slow-medium-fast) within the flexible e-training simulation model is different.

(2) There are no statistically significant differences at the level of (0.05) between the mean scores of the experimental groups in the skill performance relevant to animation design skills because the view pattern variable (Previous - Next) within the flexible e-training simulation model is different.

(3) There are no statistically significant differences at the level of $(0.05)$ between the mean scores of the experimental groups in the skill performance relevant to animation design skills due to the interaction between the display speed pattern variable (slow-medium-fast) and the information view pattern (previous - next) within a flexible etraining simulation model.

\section{RESEARCH METHODOLOGY}

The current research uses the experimental approach to test the causal relationship between the independent and dependent variables.

The experimental design of the research

According to independent variables, the factorial experimental design $(3 \times 2)$ was used as follows:

Table 1. The experimental design of the research

\begin{tabular}{|c|c|c|}
\hline $\begin{array}{r}\text { The display } \\
\text { speed } \\
\text { pattern } \\
\text { variable }\end{array}$ & $\begin{array}{c}\text { Previous at the } \\
\text { beginning of the } \\
\text { training } \\
\text { situation }\end{array}$ & $\begin{array}{c}\text { Next at the end of } \\
\text { the training } \\
\text { situation }\end{array}$ \\
\hline slow & G1 & G 2 \\
\hline Medium & G3 & G4 \\
\hline Fast & G 5 & G 6 \\
\hline
\end{tabular}

Whereas:

1. The first experimental group (G1) : This group uses the flexible e-training in the slow-motion simulation model and the previous view pattern at the beginning of the training situation.

2. The second experimental group (G2): This group uses the flexible e-training in the slow-motion simulation model and the next view pattern at the end of the training situation.

3. The first experimental group (G3): This group uses the flexible E-training in the medium-speed simulation model and the previous view pattern at the beginning of the training situation.

4. The second experimental group (G4): This group uses the flexible E-training in the medium-speed simulation model and the next view pattern at the end of the training situation. 
5. The first experimental group (G5): This group uses the flexible E-training in the fast-speed simulation model and the previous view pattern at the beginning of the training situation.

6. The second experimental group (G6): This group uses the flexible E-training in the fast-speed simulation model and the next view pattern at the end of the training situation

\section{THEORETICAL FRAMEWORK AND PREVIOUS STUDIES}

\subsection{Computer simulation programs}

Computer simulation programs are the most modern trend in electronic training systems, which aim at putting the trainee in flexible situations, imitating the actual training situations in terms of interacting with the content and is concerned with the proper representation of performances and with procedures that are characterized by simplicity and ease in light of specific rules and consistent with the trainee's own abilities which help to acquire the skills [8].

The study of Les[9], has concluded that simulated electronic modeling has a positive effect on increasing satisfaction from training and acquiring skills by presenting nontraditional training situations in ways that stimulate the learner's thinking and motivate him to practice. They also reduce the time of explanation and increase the time of practical training. The trainees have the audacity to practical training and to replicate the attempts to reach the accurate performance of the skill.

Windschitl, M., \& Andre, t.[10], have classified computer simulation programs in terms of the level of interaction to: first, motion simulation which is similar to virtual reality where tools are added to the computer so that the trainee can interact with them and at the same time allowing him to integrate into the interactive virtual environment. Second, practise simulations of phenomena which cannot be observed directly. Third, procedural simulation, which is based on 3D animation, are used to acquire performance skills in the form of several sub-skills or a series of performances to reach a specified main performance. This type of simulation does not require additional tools as it only depends on the design of a training environment that includes training situations similar to actual reality and several levels of interaction to ensure the integration of the trainee in the training situation which is the closest to the field of the current research. The trainee is asked to click on the geometry or shape category to be developed then the properties of the object and the basic variables appear where they can be controlled and adjusted as well as instant preview for that.

Animation is the most important element of the simulation. The study of Keller[11], confirmed the importance of using animated three-dimensional drawings in the development of the visual display skills from multiple angles to draw the attention of the trainee towards the important aspects, the display of dynamic models, forming the correct perceptions of abstract information which enhances training outcomes. The study of Jim [12], concluded that three-dimensional simulation forms attracting virtual environments to learn complex skills which are difficult to train on in real training environments. Ochaya [13], study showed the effectiveness of $3 \mathrm{D}$ animation in providing the trainees with adequate expertise to develop their skill abilities in performing the skills well through introducing technical strategies which increase the motivation of trainees for training.
Computer simulations use two types of animation[14]:Twodimensional animation (Shots Animation): Graphical computer programs are used in image processing and configuring them in the form of a series of frames or shots and adding simple morphological differences between each frame and the next frame at a flow rate of at least 12 frames per second and no more than 70 frames per second which is the maximum so that the eye can accommodate the speed of movement and every frame exceeds the rate of movement from the previous one in a very simple rate and thus appear to the user as if moving through the so-called visual deception. It depends on the fact that vision stays on the retina a time estimated as one of ten of the second after seeing it and then the mind transforms the successive images into motion

3D animation: This is done through the mathematical representation of a 3D surface (length, width and depth) to produce a so-called 3D model that can be viewed from any angle. 3D animation is concerned with building a virtual world in which models interact with each other .

\subsection{The average speed of the motions display in model simulation}

Motion in simulation programs is one of the multimedia elements which are used to support 3D presentations that attract trainees' attention and facilitate performance processes and performing them with high degree of skill in less time [8],

Moreno \& Mayer[5], concluded that the simulation of the display speed rate increases visual stimuli and creates relationships between the abstract and the perceptible. It also helps to perceive dynamic skills and provides a better training environment where the skills are displayed continuously and connected with each other and achieves the interaction. Motion also works on bridging the gap which the trainee suffers from in the traditional training environment as a result of the intermittent explanation of concepts and skills, which improves the perception and performance and raises the selfefficacy of the trainees. Motion increases the attention and motivation of the trainee and provides performance models. Animated displays also keep on the sequence of information within the memory of trainees which decreases the burden on the memory and makes it focus on information extraction clearly.

The results of the Eka [6], study also found that the speed the elements display within the simulation model affects the speed of information processing and that performance levels are linked to the speed of knowledge and skills display. This is supported by the Mayer et al.[7], study, which concluded that the medium average speed of the animation affects the processes of perception and learning compared to the low average speed. Rasch \& Schnotz [15], believed that fast or slow motion of the animation affects positively on the process of preparing the information and processing it in the shortterm memory of the trainees, while slow motion does not match the characteristics of the sensory receptors of the old trainees, which makes it very difficult to understand what is being training on.

It is clear from the above that the display speed of the simulation model is a means to display the information, to focus attention of the field of vision, to achieve the effectiveness of the display and to achieve some kind of coherence to understand the abstract performance processes, which affects the speed of knowledge and skills perception. 


\subsection{The information view pattern in the simulation model}

The information view pattern in the simulation model is a way to organize the display of training content elements clearly, conceptually, and with a strong influence on the trainees, and to display them either verbal (audible/legible) or visually (using images, fixed and animated graphics). There are two types to provide that information: the previous view on which items are displayed at the beginning of the training situation and before the content is displayed in detail. This pattern is used with the aim of shaping the concepts of the specific subject. It achieves many advantages such as: raising the performance of trainees, increasing the ability of trainees to analyze, form and contribute to the transition of the training effect. The type is called Next-view which is displayed at the end of the training situation with the aim of organizing the knowledge structure of the trainee, linking and summarizing what they have been trained on [16],[17].

There is a difference between the results of the studies with regard to the effect of information view pattern in the simulation model on which the (next-previous) patterns are affected by many variables such as the characteristics of the trainees, the nature of the training content and the speed of the display in the simulation model. The results of Kang, 1997 study concluded that there was a difference between the group that used the previous view simulation and the group that used the next view simulation in raising the training efficiency. Barbosa [16], study confirmed the importance of the next view- information because of its effect on skills development.

The researcher considers that the current research differs from previous studies and research in terms of the nature of the training content, the target group and simulation model variables: the information view pattern and the average of the display speed motion in the development of animation design skills.

The researcher interviewed an exploratory sample of computer teachers at general education schools to identify the main difficulties which encounter them in the design of animation, which were as follows: inability to predetermine the pattern and the nature of the model to be designed, not being able to determine the starting point in the design of the animated models, the difficulty of determining the ideal ratios for the model and achieving coordination between its dimensions, the difficulty of clarifying structural features in the drawing the model, the difficulty of identifying the characteristics and physical traits of the model so that they are clear, the inability to form lines that serve as indicators of the main points in the details of the geometry, the difficulty of adjusting movements and sounds that requires more time to train students on, the inability to adjust the direction of the movement and its end, not inserting the geometry in its right place in the scene which affects the delivery of the necessary information and the difficulty of final rendering of the scene. All of which represents difficulties for the trainees and reduces their motivation for training and skills acquisition .

\section{RESEARCH PROCEDURES}

\subsection{Developing the simulation model}

After reviewing the previous studies relevant to writing training programs for skills development and educational design models, I have adopted the general model of educational design ADDIE Model to design and apply the proposed simulation programme for several reasons, including: the ADDIE model covers at all stages of the educational design in line with the system approach and the steps of systems methods (analysis-design-developmentimplementation-evaluation).The ADDIE Model is suitable for the nature of web-based training. It integrates the different training theories. I have also added some subtasks in line with the research variables to develop animation design skills across online training environments which simulate actual reality.

\subsubsection{Analysis stage: includes the following tasks:}

1. Analyzing the performance to identify the training needs.

2. Defining the training objectives for the simulation model: the overall objectives that the proposed simulation system seeks to achieve have been defined. They included skill-related objectives which were identified through the analysis of the basic and sub-skills for animation design by using task analysis method. The task analysis list was prepared in its final form (appendix 1).The objectives of the model were formulated in performance phrases that accurately determine the required change to the trainee's performances so that it can be observable and measurable

3. Characterization of trainees: They are the research sample from 2010 graduates of the computer teacher Preparation Department in the College of Specific Education in Damietta University and those who have previous experience in dealing with animation programs and the desire to achieve professional development.

4. Analyzing the real tasks that will be trained on to improve performance

5. Identifying the correct practical steps to practice the required skills to help avoid wrong practices during the design process.

6. Identifying the elements of the proposed simulation model in line with the actual environment

\subsubsection{The design stage: includes the following tasks:}

1. Preparing the Simulation Model diagram: I have used the ARENA Simulation Software to analyze and model the processes. I have used it to design the simulation model as a flowchart for the elements of the simulation models: geometries, forms, materials and practical steps needed to simulate training. The ARENA program allows inputting elements in a manner that allows the simulation of systematic and random changes which occur in actual reality and the possibility of simulating changes in the programme of training. The program includes several different measurements of performance to evaluate the simulation process such as the arithmetic average of a skill performance time measurement and the average of skill performance.

2. Preparing the content of the simulation model: The training content has been determined through meetings with experts, specialists in computer and animation programs and some computer teachers. In light of this, the content elements are as follows: Shaping the lines that represent the main points in the design of the models and shapes -determining the ideal proportions of the object and the coordination between its dimensionsadjusting the geometry properties -Adding sound and motion effects and adjusting their start and end -adding cameras to the scene-adding the materials to the modelsthe final rendering of the scene. 
3. Choosing the simulation pattern: The simulation pattern is determined by analyzing the training tasks for $3 \mathrm{~d}$ animation design skills and the diagram design process of animation, content analysis and defining the required simulated situations that focus on acquiring the performance skills of the animation design and rendering them correctly. Therefore, the procedural simulation pattern has been chosen, which allows the trainee to follow the steps and skills of 3D animation design with motion and sound effects .

4. Preparing the scenario on which the simulation model is produced: In light of both the objectives, the training attitudes and the content analysis, the simulation model scenario could be prepared in the following method :

\subsection{3 - The development stage. It includes the} following:

1. Identifying the training strategy in the simulation model: A simulation strategy has been used in which situations similar to the real ones are displayed. An etraining environment has been designed that includes training situations that make the trainee actively participate in the training. The strategy was designed through a full perception of the situations similar to actual reality with all its temporal and spatial dimensions, the tools and persons used in the simulation and putting instructions to the trainee on how to start and what is required to be ready to start properly as well as putting many possibilities by the trainer so that the trainee can overcome most of the potential difficulties .

2. Employing the simulation method and that requires the following: Illustrating the purpose of the simulation model

3. identifying the difficulties to be converted to a simulation method-Specifying the training environment to simulate-identifying the tools used in simulationSpecify the behavior to be emulated by the traineewriting a simulation scenario-identifying the proposed alternatives from which a trainee can choose-writing feedback for correct or incorrect responses-clarifying the information available to the trainees in the simulation model

4. Designing the simulation model's interface panels: Submission Panel, Basic Process Panel, Advanced Process Panel, Effects Panel, Materials Panel, Rendering Panel

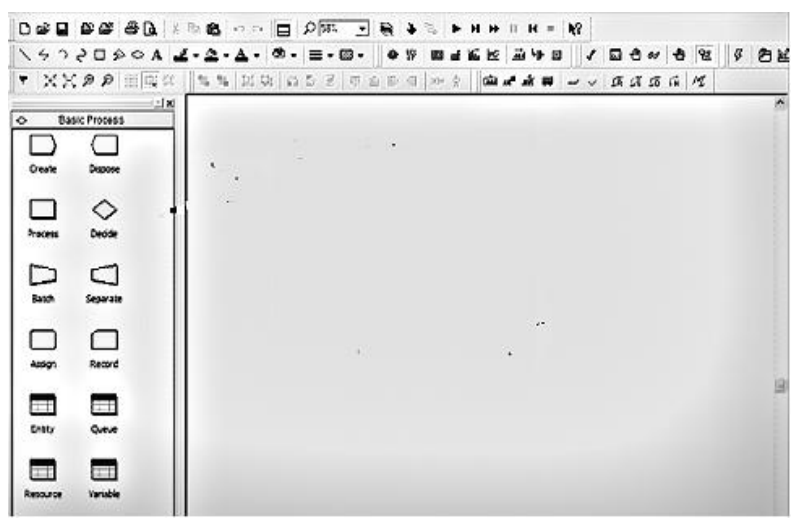

Fig 1: The main interface in the simulation model
5- Designing the interaction tools in the model :

-The training content selection tool for the view : the view display pattern at the beginning of the training situation (previous view), the view display pattern at the end of the training situation (next view)

- The speed display selection tool: Three designs have been added to the rendering processes in the simulation model: first (slow speed at 16 frames per second), second (medium speed at 16 frames per second), third (fast speed at 24 frames per second)

-The dialog boxes that interact with the trainee, which are one of the most important elements in the training simulation programs. They are as follows:

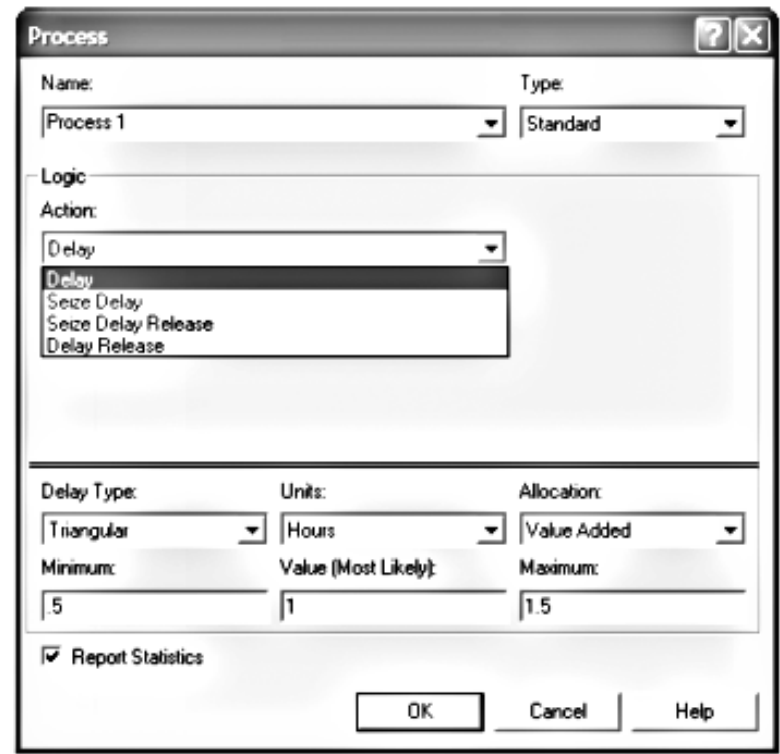

Fig 2: Shows the selection of the process

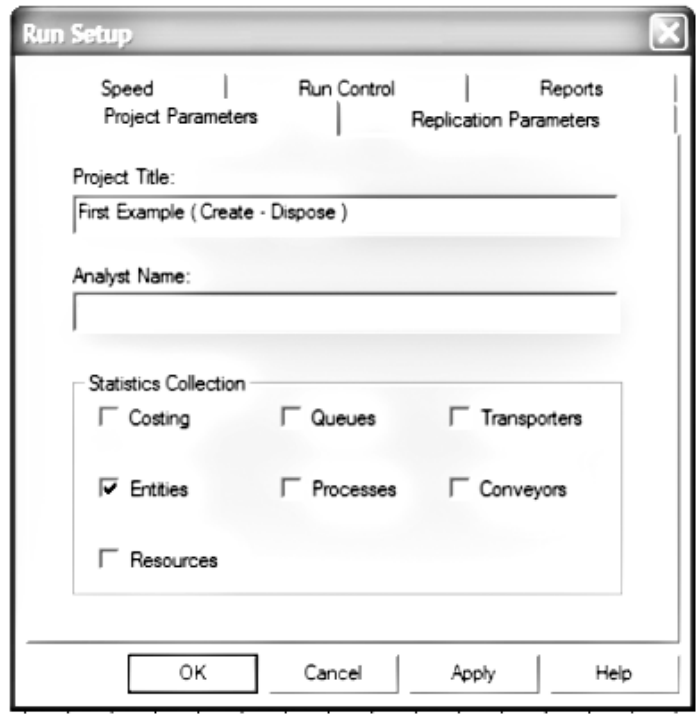

Fig 3: Adjusting the geometry speed options

\subsubsection{Implementation stage:}

The training media was implemented in the simulation model, which was chosen in the educational design stage through the following programs:

-Microsoft word: to prepare the text content 
-Photoshop :to create sample images and static illustrations.

-3D Studio Max: to create 3D animation models .The program is based on vector graphics or curves and creating animated geometries for websites usages. It can also deal with many types of audio files and it can control video files.

-Comtasia Studio: to analyze the real system and simulations. The program allows recording the desktop and adding effects and achieving video quality.

-Auto play media studio: It is one of the authoring programs that allows the initial production of the simulation model.

\subsubsection{Evaluation stage}

The proposed simulation model was presented to the research referees to verify the clarity of the content (the simulation model in the performance of the skill) and the ability to interact with the interaction tools in anticipation of the final application.

\subsection{Research tools}

The research tool is a performance note card to measure the performance of animation design skills and its preparation steps are as follows:

1. Identifying the overall objective of the card: The card aims to measure the performance of computer teachers experimental groups - the animation design skills included in the proposed simulation model.

2. Determining the method of observation: the analytical method of splitting the work into its component tasks has been observed. The animation design skill performance of the study sample was observed after applying the proposed web simulation model .

3.The initial form of the card: In light of the training objectives, task analysis and training content of the simulation model, a note is designed to perform basic skills. The card in its initial form consisted of 17 basic skills. 45 sub-skills describing a clear, specific and correct performance of the trainee. Table (2) shows the steps to perform animation design skills and the value in degrees

Table 2. Shows the steps to perform the skills of animation design and the $P$ value in degrees

\begin{tabular}{|c|c|c|c|}
\hline No & Basic Skills & $\begin{array}{c}\text { Num } \\
\text { ber of } \\
\text { Steps }\end{array}$ & $\begin{array}{c}\text { The P Value } \\
\text { in Degrees }\end{array}$ \\
\hline $\mathbf{1}$ & the design of binary shapes & 5 & 10 \\
\hline $\mathbf{2}$ & $\begin{array}{c}\text { Converting binary shapes } \\
\text { into objects }\end{array}$ & 4 & 8 \\
\hline $\mathbf{3}$ & $\begin{array}{c}\text { Adjust the properties of the } \\
\text { standard geometries. }\end{array}$ & 5 & 10 \\
\hline $\mathbf{4}$ & $\begin{array}{c}\text { Importing geometries from } \\
\text { external sources }\end{array}$ & 4 & 8 \\
\hline $\mathbf{5}$ & $\begin{array}{c}\text { Selecting items within the } \\
\text { scene }\end{array}$ & 5 & 10 \\
\hline $\mathbf{6}$ & $\begin{array}{c}\text { Using conversion tools for } \\
\text { items(Move - Rotate - } \\
\text { Uniform Scale ) }\end{array}$ & 5 & 8 \\
\hline $\mathbf{7}$ & $\begin{array}{c}\text { Determining the Pivot } \\
\text { Point. }\end{array}$ & 4 & 8 \\
\hline $\mathbf{8}$ & $\begin{array}{c}\text { positions in the scene using } \\
\text { the Direction system of } \\
\text { conversion axes }\end{array}$ & 4 & 10 \\
\hline $\mathbf{9}$ & Add lighting types to the & 5 & \\
\hline
\end{tabular}

\begin{tabular}{|c|c|c|c|}
\hline & $\begin{array}{l}\text { scene ( Standard- } \\
\text { Photometric) }\end{array}$ & & \\
\hline 10 & $\begin{array}{l}\text { Adjust lighting properties ( } \\
\text { Intensity / Color / } \\
\text { Attenuation ) }\end{array}$ & 4 & 8 \\
\hline 11 & $\begin{array}{l}\text { Adding shadows to the } \\
\text { scene and adjusting their } \\
\text { properties ( Color-Size- } \\
\text { Map -Light Affects } \\
\text { Shadow Color - } \\
\text { Atmosphere Shadows) }\end{array}$ & 4 & 8 \\
\hline 12 & $\begin{array}{c}\text { Adding all kinds of } \\
\text { cameras to the scene ( } \\
\text { Target Camera-Free } \\
\text { Camera ) }\end{array}$ & 5 & 10 \\
\hline 13 & $\begin{array}{l}\text { Adjusting the camera } \\
\text { properties in the scene } \\
\text { (focal length (Focal Length } \\
\text {-Field of vision) }\end{array}$ & 4 & 8 \\
\hline 14 & $\begin{array}{l}\text { Add motion to scene ( } \\
\text { Auto Key-Set Key ) }\end{array}$ & 5 & 10 \\
\hline 15 & Adding sound to the scene & 5 & 10 \\
\hline 16 & $\begin{array}{l}\text { Adding materials to the } \\
\text { items in the scene }\end{array}$ & 6 & 12 \\
\hline 17 & Rendering & 6 & 12 \\
\hline & Total & 80 & 160 \\
\hline
\end{tabular}

Each correct step performed by the trainee was valued by two marks. In case of an incomplete step, it was valued by one mark and in case of incorrect performance, no mark was given

Table 3. The quantitative estimation of the note card

\begin{tabular}{|c|c|c|c|}
\hline Performance level & Right & Incomplete & wrong \\
\hline $\begin{array}{c}\text { Quantitative } \\
\text { estimation }\end{array}$ & 2 & 1 & 0 \\
\hline
\end{tabular}

The total score for each basic skill is calculated for all students and thus the level of skill performance is estimated.

- Card Verification: The card has been presented in its initial form to a group of specialized referees to verify the suitability of the card items for the training objectives and the accuracy of the wording of its terms and according to their opinions, the card was prepared in its final form.

- The Stability of the Card Note: the stability of the card has been calculated in the multi-referees manner on the performance of one trainee, on which three of the research specialized referees in the field of animation observe the performance of three trainees who were exposed to the training content and then calculated the coefficient of agreement on the performance of each trainee individually and by using the Cooper equation, the averaged coefficient ratio between the referees was 83.27 which means it's pretty much stable.

\subsection{Choosing the research sample}

The research sample consisted of (30) computer teachers in the secondary schools in Damietta governorate who were deliberately selected through the computer supervision in the Directorate and were distributed randomly to (6) experimental groups according to the experimental design of the research and its independent variables. 


\section{VIEWING AND EXPLAINING THE RESULTS OF THE SKILL PERFORMANCE}

The results of the skill performance of the experimental groups have been analyzed according to averages and deviations and according to the variable of display speed of the motion in the simulation model (slow/medium/fast), and the information view pattern variable (previous/Next) as follows:

\subsection{The effect of the motion display speed pattern (slow-medium-fast) in the flexible E-training simulation model on the skill performance associated with animation design skills.}

The results of the groups have been analyzed for the skill performance associated with the animation design skills for the averages and deviations. Table (4) shows the results as follows:

Table 4. Means and standard deviations of the skill performance degrees According to the motion display speed pattern in the model simulation

\begin{tabular}{|c|c|c|c|}
\hline $\begin{array}{c}\text { motion display } \\
\text { speed pattern }\end{array}$ & NO. & Average & Std. Deviation \\
\hline slow & 10 & 206.97 & 4.25 \\
\hline Medium & 10 & 2016.34 & 3.45 \\
\hline Fast & 10 & 236.84 & 3.88 \\
\hline
\end{tabular}

Table (4) shows that the average grades of students with the fast view pattern (236.84) is larger than the average grades of students with the slow view pattern (206.97), and the average grades of students with the medium view pattern (2016.43)

To find out the significance of the differences between the grades average of the display speed groups in the skill note card, the one-way analysis of variance (ANOVA) is used as shown in the following table (5)

Table 5. The results of a one-way variance analysis to detect the significance of the differences between the mean scores of the display speed pattern (slow-medium-fast)

\begin{tabular}{|c|c|c|c|c|c|}
\hline Source & $\begin{array}{c}\text { Sum } \\
\text { of } \\
\text { square }\end{array}$ & df & $\begin{array}{l}\text { Mean } \\
\text { square }\end{array}$ & F & Sig. \\
\hline $\begin{array}{c}\text { Between } \\
\text { groups }\end{array}$ & 2741.6 & 5 & 548.32 & \multirow{3}{*}{32.4} & \multirow{3}{*}{$\begin{array}{c}000 \\
0 \\
\text { Sig. }\end{array}$} \\
\hline $\begin{array}{l}\text { Within } \\
\text { groups }\end{array}$ & 7,405 & 24 & 16.9 & & \\
\hline Total & 3,3147 & 29 & & & \\
\hline
\end{tabular}

Table (5) shows the statistical significance (000.0) is less than the specified significance level (0.05), which confirms the effect of the display speed pattern in the simulation model of the skill performance.

Thus, $\mathrm{H} 1$ of the research is rejected, i.e. there are statistically significant differences at the level of $(0.05)$ between the mean scores of experimental groups in the skill performance associated with animation design skills because the display speed pattern (slow-medium-fast) within the flexible etraining simulation model is different.

\subsection{The effect of the (previous / next) information view pattern within the flexible e-training simulation model on the skillful performance associated with animation design skills. \\ The $\mathrm{T}$ test was applied for independent samples .The} results were as follows:

Table 6. Shows the results of the T-test for the independent sample to determine the significance of the differences between the mean scores of the students of the information view pattern (previous / next) in the performance note card for animation skills

\begin{tabular}{|c|c|c|c|c|c|c|}
\hline $\begin{array}{c}\text { Information } \\
\text { view pattern }\end{array}$ & $\mathbf{N}$ & Mean & $\begin{array}{c}\text { Std. } \\
\text { Deviation }\end{array}$ & df & $\mathbf{t}$ & $\begin{array}{c}\text { Level } \\
\text { of sig. }\end{array}$ \\
\hline Previous & 15 & 487.6 & 6.11 & \multirow{2}{*}{28} & 13.12 & 0.001 \\
\hline Next & 15 & 302.1 & 7.35 & & 0.35 \\
\hline
\end{tabular}

Table (6) shows that:

1. The mean score of the students with the previous view pattern group (487.6) is larger than the mean score of students with the next view pattern groups (268.03)

2. The statistical significance (000.0) is less than the level of specified significance $(0.05)$, which confirms that there is a main effect of information view pattern in the simulation model (previous / next) on the skill performance and thus $\mathrm{H} 2$ of the research is rejected. It means there are statistically significant differences at the level of 0.05 between the mean scores of experimental groups in related to the animation design skill. These differences are because view pattern (previous-next) within the flexible e-training simulation model is different.

\subsection{The effects of the interaction between the display speed variable and the variable of information view pattern.}

The results of the six groups were analyzed according to the mean and standard deviations and according to the two variables: the variable of display speed (slow-medium-fast) pattern and the view pattern (previous-next), the following results were achieved :

Table 7. The arithmetic mean and standard deviation of card scores of the animation design skills note of each group according to the display speed pattern and the information view pattern in the simulation model.

\begin{tabular}{|c|c|c|c|c|}
\hline $\begin{array}{c}\text { Display speed } \\
\text { pattern }\end{array}$ & $\begin{array}{c}\text { View } \\
\text { Pattern }\end{array}$ & No. & Mean & $\begin{array}{c}\text { Std. } \\
\text { Deviation }\end{array}$ \\
\hline \multirow{2}{*}{ slow } & previous & 5 & 212.51 & 4.23 \\
\cline { 2 - 5 } & Next & 5 & 201.42 & 3.62 \\
\hline \multirow{2}{*}{ Medium } & previous & 5 & 218.05 & 3.13 \\
\cline { 2 - 5 } & Next & 5 & 214.63 & 4.54 \\
\hline \multirow{2}{*}{ fast } & previous & 5 & 252.63 & 4.06 \\
\cline { 2 - 5 } & Next & 5 & 221.05 & 3.71 \\
\hline
\end{tabular}

Table (7) shows that the mean score of the fast display speed pattern groups is larger than that of the previous method of information view at (252.63), followed by the medium display pattern groups at (218.05), while the slow display pattern with the next view information method ranked last at (201.42).

To determine the significance of the differences between the groups, the Two-way analysis of variance was used to measure the interaction between the research variables: 
display speed pattern variable (slow-medium-fast) and the information view variable pattern (previous-next) in addition to measuring the effect of each variable on the other, table (8) shows the results of two-way analysis of the skill performance.

Table 8. The results of the Two-way analysis of variance to detect the significance of differences between the experimental groups in the skill performance.

\begin{tabular}{|c|c|c|c|c|c|}
\hline Source & $\begin{array}{c}\text { Sum of } \\
\text { Square }\end{array}$ & df & $\begin{array}{c}\text { Mean } \\
\text { Square }\end{array}$ & F & Sig. \\
\hline $\begin{array}{c}\text { display speed } \\
\text { pattern }\end{array}$ & 1066.13 & 2 & 533.065 & 31.9 & $\begin{array}{c}\text { Sig. at } \\
0.001\end{array}$ \\
\hline $\begin{array}{c}\text { Information } \\
\text { view pattern }\end{array}$ & 721.40 & 1 & 721.40 & 43.17 & $\begin{array}{c}\text { Sig. at } \\
0.001\end{array}$ \\
\hline $\begin{array}{c}\text { Interaction } \\
\text { between the } \\
\text { display speed } \\
\text { pattern and the } \\
\text { view pattern }\end{array}$ & 231.08 & 2 & 115.54 & 6.91 & $\begin{array}{c}\text { Sig. at } \\
0.001\end{array}$ \\
\hline error & 401.11 & 24 & 16.71 & & \\
\hline total & 2419.72 & 29 & & & \\
\cline { 1 - 2 }
\end{tabular}

Using table results (8) It is clear that the calculated F of the effect of the interaction between the display speed pattern and the view pattern of the information in the simulation model has been valued $(6.91)$ The significance level $(0,000)$ is less than $(0.05)$ which means that $\mathrm{H} 3$ is rejected, i.e. there are statistically significant differences at the level of 0.05 between the mean scores of experimental groups in the skill performance related to animation design is due to the interaction between the display speed pattern (slow-mediumfast) and the information view (previous-next) within the flexible e-training simulation model.

To find out the direction of variances and for any of the groups, the Scheffe test was used for pairwise comparisons as shown in Table 9 below:

Table 9. Shows the binary comparisons between the experimental groups resulting from the binary interaction between the display speed pattern variable (slow-mediumfast) and the (previous-next) view pattern variable of the skill performance within the simulation model.

\begin{tabular}{|c|c|c|c|}
\hline G & Groups & $\begin{array}{c}\text { The average } \\
\text { difference }\end{array}$ & Sig. \\
\hline $\begin{array}{l}\text { G 1: Slow speed } \\
\text { /Previous view }\end{array}$ & $\begin{array}{l}\text { G2: Slow speed / Next view } \\
\text { G3: Medium speed / Previous } \\
\text { view } \\
\text { G 4: Medium speed / Next view } \\
\text { G 5: Fast speed / Previous view } \\
\text { M 6: Fast speed / Previous view }\end{array}$ & $\begin{array}{l}9.07 \\
* 7.11 \\
10.04 \\
* 4.30 \\
* 5.91\end{array}$ & $\begin{array}{l}\text { Not } \\
\text { Sig. } \\
\text { Sig. } \\
\text { Not } \\
\text { Sig. } \\
\text { Sig. } \\
\text { Sig. }\end{array}$ \\
\hline $\begin{array}{l}\text { G 2: Slow speed } \\
\text { /Next view }\end{array}$ & $\begin{array}{l}\text { G 1: Slow speed / Previous view } \\
\text { G3: Medium speed / Previous } \\
\text { view } \\
\text { G 4: Medium speed / Next view } \\
\text { G5: Fast speed / Previous view } \\
\text { M 6: Fast speed / Previous view }\end{array}$ & $\begin{array}{l}10.05 \\
* 8.21 \\
12.04 \\
* 6.30 \\
* 4.91\end{array}$ & $\begin{array}{l}\text { Not } \\
\text { Sig. } \\
\text { Sig. } \\
\text { Not } \\
\text { Sig. } \\
\text { Sig. } \\
\text { Sig. }\end{array}$ \\
\hline $\begin{array}{c}\text { G3: Medium } \\
\text { speed / Previous } \\
\text { view }\end{array}$ & $\begin{array}{l}\text { G 1: Slow speed / Previous view } \\
\text { G 2: Slow speed / Next view } \\
\text { G 4: Medium speed / Next view } \\
\text { G5: Fast speed / Previous view } \\
\text { G 6: Fast speed / Previous view }\end{array}$ & $\begin{array}{l}* 8.20 \\
11.01 \\
* 6.22 \\
* 4.30 \\
* 6.04\end{array}$ & $\begin{array}{l}\text { Sig. } \\
\text { Not } \\
\text { Sig. } \\
\text { Sig. } \\
\text { Sig. } \\
\text { Sig. }\end{array}$ \\
\hline $\begin{array}{c}\text { G 4: Medium } \\
\text { speed / Next } \\
\text { view }\end{array}$ & $\begin{array}{l}\text { G 1: Slow speed / Previous view } \\
\text { G2: Slow speed / Next view } \\
\text { G3: Medium speed / Previous } \\
\text { view } \\
\text { G5: Fast speed / Previous view } \\
\text { G 6: Fast speed / Previous view }\end{array}$ & $\begin{array}{l}11.53 \\
13.09 \\
* 4.93 \\
* 5.32 \\
* 3.62\end{array}$ & $\begin{array}{l}\text { Not } \\
\text { Sig. } \\
\text { Not } \\
\text { Sig. } \\
\text { Sig. } \\
\text { Sig. } \\
\text { Sig. }\end{array}$ \\
\hline $\begin{array}{c}\text { G5: Fast / } \\
\text { Previous view }\end{array}$ & $\begin{array}{l}\text { G 1: Slow speed / Previous view } \\
\text { G2: Slow speed / Next view } \\
\text { G3: Medium speed / Previous } \\
\text { view }\end{array}$ & $\begin{array}{l}* 5.21 \\
* 4.80 \\
* 6.11 \\
* 5.61 \\
\end{array}$ & $\begin{array}{l}\text { Sig. } \\
\text { Sig. } \\
\text { Sig. } \\
\text { Sig. }\end{array}$ \\
\hline
\end{tabular}

\begin{tabular}{|c|l|c|c|}
\hline & G 4: Medium speed / Next view & $* 4.52$ & Sig. \\
\hline & G 6: Fast speed / Previous view & & Not \\
& G 1: Slow speed / Previous view & 13.02 & Sig. \\
& G2: Slow speed / Next view & 14.20 & Not \\
G: Fast / Next \\
view & G3: Medium speed / Previous & $* 6.12$ & Sig. \\
& view & $* 5.24$ & Sig. \\
& G 4: Medium speed / Next view & $* 4.08$ & Sig. \\
& G5: Fast speed / Previous view & & Sig. \\
\hline
\end{tabular}

*The Median is statistically significant at the level of 0.05

Table (9) shows that there are statistically significant differences at the level of 0.05 between the experimental group (G5), which dealt with the fast speed simulation model and the previous view, and the other five groups for Group 5.

\section{INTERPRETING RESULTS}

\subsection{The results related to the effect of the display speed pattern (slow-medium- fast) in the flexible e-training simulation model on the skillful performance associated with animation design skills.}

The results of table (8) indicate that H1of the research is rejected as there are statistically significant differences at the level of 05.0 between the mean scores of experimental groups in the skill performance associated with animation design skills because the display speed pattern (slow-medium-fast) within the flexible e-training simulation model is different.

To determine the direction of these differences, the results of table 4 were reviewed. It was found that the largest mean score (236.84) came in favour of the Five and six Groups who were trained on the $3 \mathrm{D}$ simulation model with the fast display speed (24 frames per second).

This result is consistent with Mayer et al. [7], which shows that the display speed in simulations models affects the process of perception and training. Slow motion divides the understanding and perception processes, which in turn affects practicing the skill. Viewing the skills as a fast and continuous flow generates a full understanding of the idea within the mind and the implementation of its practical procedures at the same time. Therefore, that result must be taken into account in the development of training simulation programs, which may be due to the following:

The fast display speed of the simulation model is suited to the skill capabilities of the computer teachers in the field of computers and their ease of understanding the required tasks which in turn led to correct responses to the specific skills. The display speed of the simulation model in displaying the skill avoids linear display of the information or its fragmentation into separate blocks as it helps the trainees to get rid of the stress of training and to create positive emotions. In addition, the fast speed of the simulation model aimed directly at focusing on the creative mind and the practical performance of the trainee and not on the cognitive achievement that requires a balance between the amount of information provided at a specific time.

Eka [6], emphasizes that the fast display of the simulation model helps the trainees to put the new skills in an integrated way in their minds and integrate them with their previous experiences through skills building activities that include simulating the real world. The fast display leads to a good visual representation which helps the trainee to form a mental model of the skill and visually coding it, which may be difficult through slow display. 
The speed display has also affected the speed of the trainees' perception of the skills presented and achieved some kind of visual symmetry for the required practical procedures. The speed of the visual representation of the skills helps to quickly process them and to establish relationships between them, while the slow display reduces the processing and handling of the information and affects the acquisition of skills especially with experienced trainees who may find it very difficult to understand what they are training at a slow speed. The fastspeed simulation model has also helped to transfer the trainees' abilities to high levels of analysis and synthesis through the speed of perception of abstract relationships between elements and the speed of tracking all levels of design in forming the models and detecting relative relationships in the shape dimensions and developing inference skills which is the opposite of the traditional hierarchy in training .

\subsection{The results related to the effect of the information view pattern (previous- next) in the flexible e-Training simulation model on the skill performance associated with animation design skills.}

Table (6) indicates that there are statistically significant differences at the level of 0.05 between the mean scores of the experimental groups in the note card because the view pattern (previous-next) is different in the simulation model. To determine the direction of these differences, it was clear that the largest median was for the group which were trained with the simulation model with the previous training situation (previous view situation) The mean score for them in the performance card was (487.6), while the mean of the groups trained with the simulation model at the end of the training situation (Next training situation) was (302.1).

Thus, $\mathrm{H} 2$ is rejected, i.e., there are statistically significant differences at the level of 0.05 between the mean scores of the experimental groups in the skill performance associated with animation design skills because the view pattern (previousnext) was different within the flexible e-training simulation model for the previous view situation.

The results of the current research are consistent with the study of both [1], [2] , [12], which confirmed that the previous view in the educational situation had a positive and statistically significant effect on the skill performance of the writing skills of the English alphabet compared to the next view, which may be due to the following:

1. The previous view pattern of the $3 \mathrm{D}$ simulation model at the beginning of the training situation helped to elicit the previous experiences of the trainees and activate their abilities and their speed of perception of the practical applications of abstract scenarios and getting, organizing and processing the information in a realistic way

2. The 3D simulation model enables the viewing of the geometry from different angles and dynamically draw the attention of the trainees towards the important aspects, thus increasing the activity of the trainees. On the other hand, the previous presentation of the simulation model is an active training strategy aimed at increasing the motivation of the trainee and building the correct perceptions of the abstract information to improve skills [19]
3. The previous view of the information in the simulation model has helped to stimulate short-term memory for trainees, to increase their ability to encrypt information and to speed up the storage and retrieval of information in a better way in the long-term memory .

\subsection{The results related to the effect of binary interaction between the variable of the display speed pattern (slow-medium-fast), and the information view pattern variable (previous-next) on the skill performance of the simulation model.}

Analyzing the results of table (5) and table (9), it is clear that there are statistically significant differences at level 05,0 between the mean scores of experimental groups in the skill performance associated with animation design skills due to the interaction between display speed pattern (slow-mediumfast) and the view pattern (previous-next) within the flexible e-training simulation model for group 5, which were trained with the fast-display speed simulation model and previous situation pattern, thus achieving the largest scores in skill performance compared to other groups. That result may be due to the following reasons:

1. The interaction between the display speed pattern (slowmedium-fast) and the pattern of view (previous-next) in the simulation model, on one hand, has helped to adjust both the cognitive abilities of trainees and on the other hand to direct their responses well towards the correct performances and training activities .

2. The previous view situation at the beginning of the fastspeed training situation in the $3 \mathrm{~d}$ simulation model has helped the trainee to speed up the process of forming the shape of the displayed skill, good visual representation of the visual field, increase in the pattern of attention, improve cognitive functions and generate appropriate responses that have led to new skills. All of these may be difficult through the slow display of understanding the skills that are incompatible with their visual and mental coding [12], [18] Viewing the information at the beginning of the training situation has formed virtual 3D interactive training environments based on the accuracy of reality representation and the interaction of the trainee to perform the training tasks, to achieve its objectives, to explore the skills, to realize the speed of their perception and to transfer them to the long-term memory. They have also helped navigation which generates within the trainee a sense of integration within the training environment and interacting with it through practical methods and adapting to the virtual world, which has helped to raise the skills of the trainees, to link between skills and to acquire new skills.

\section{CONCLUSION AND FUTURE SCOPE}

This research is intended to preparing a flexible e-training simulation model in the field of animation based on the interaction between the display speed (slow-medium-fast) and the information view pattern (Previous / Next)within the flexible e-training simulation model for the group which has dealt with the fast-speed simulation model and the previous training situation. This has made the group achieve the highest grades in terms of performance skill compared to other groups

The interaction between the display speed pattern (slowmedium-fast) and the pattern of view (previous-next) in the simulation model, on one hand, has helped to adjust both the 
cognitive abilities of trainees and on the other hand to direct their responses well towards the correct performances and training activities.

Future work can be extended to study the effect of the variable of the simulator shape on the training outputs in virtual environments and Studying the effect of the procedural simulation pattern variable on the design of the fivedimensional animation.

\section{ACKNOWLEDGMENTS}

The author thank all computer teachers in the secondary schools for their collaboration in the experiments.

\section{REFERENCES}

[1] Akinsola, M. \& Animasahun, I. (July 2007): The Effect of Simulation -Games environment on students Achievement and attitudes to mathematics in secondary schools, The Turkish Online Journal of Educational Technology, 6 (3)

[2] Zacharia, C. (November, 2005): Impact of interactive Computer Simulation on the Nature and Quality of Postgraduate Science Teachers Explanations in physics, International Journal of Science Education, Vol.27, No.14

[3] Amy, I. (2009): A measure of the effectiveness of Incorporating 3D human anatomy into an under underdog laboratory, British Journal of Educational technology, Vol.40, NO.4,664-672

[4] Papastergiou, M. (2006), Course management Systems as tools for the creation of online learning environments: Evaluation from a social constructivist perspective and implications for their design, International Journal on ELearning, 5,593-622

[5] Moreno, R., \& Mayer, R. (2002): Animation as an Aid to Multimedia Learning. Educational Psychology Review , 14 (1), 37-98

[6] Eka, R., (April 2010): Gender Differences in processing speed: A Review of recent research, Learning and individual Differences, 21 (2), 145-149

[7] Mayer, K., Rasch, T., and Schnotz , W. (2010): Effects of Animations speed of presentation on perceptual processing an learning, Learning and Instruction, 20 (2), 136-145

[8] Tara, W., \& Kerry, H., (2008): Effects of a computer based reading reading program on young children,
Australasian Journal Of Educational Technology 24 (3), 258-274

[9] Les, M. (October, 2004): Computer simulation in Distance Education, International Journal of Instruction Technology \& Distance Learning, VOL.1.1, No.10.www.Itd1.org/journal/ oct 04 / articale02.htm.

[10] Windschitl, M., \& Andre, t., (1994): Using Computer Simulation to enhance Concentrating the Role of Constructivist Instruction and Student Epistemological Beliefs, journal of Research in Science Teaching, 35 (2), $145-160$

[11] Keller, A., (2005): Information Visualization for Knowledge Acquisition the Impact of Dimensimatity and Color coding, Computer in Human Behavior, 22,43-65

[12] Jim,R.,(Dec,2008):Learning English with "The Sims": Exploiting Authentic Computer Simulation Games for L12 Learning, Computer Assisted Language Learning,21(5),441-455.57-66

[13] Ochaya, W., (2006): Using 3D Graphic and Animation Software to Enhance Learning Experience in GED, http://prtdinl .rit.edu / dspace / bitstream / wochava / capstone project2006.pdf

[14] Aarnio, P. , (1999): Use of Simulation in Techtronic Machine Design, www.Automationit.Hut.Fi / Old / Julkaisut / Documents / Seminars / Sem A99 / Aarnio.Pdf

[15] Rasch, T. \& Schnotz, W. (2005): Enabling Facilitating and Inhibiting Effects of Animation in Multimedia Learning Why Reduction of Cognitive Load Can Have Negative Results on Learning.ETR \& D.53 (3), 47-58

[16] Barbosa, R., Marques, V., and Torres, B. (Jul 2005): An Advance Organizer for Teaching Bacterial Metabolism, Biochemistry and Molecular Biology Education, 33 (4), 265-268

[17] Daniel, D., (2008): Using an Advance Organizer to Facilitate Change in Students Conceptualization of the role of Creativity in Science, Chemistry Education Research and Practice, 9 (4), 291-300

[18] Baser, M., (2006): Promoting Conceptual change through active learning using open source software for physics simulations, Australasian Journal of Educational Technology, 22 (3), 336-354 